\title{
Cornerstones of Patient Blood Management in Surgery
}

Anna Butcher ${ }^{1}$, Toby Richards ${ }^{1}$

${ }^{1}$ Division of Surgery and Interventional Science, University College London, London, United Kingdom.

All related correspondence should be sent to:

Anna Butcher MBBS, Ph.D

Division of Surgery and Interventional Medicine

UCL

74 Huntley Street

London, UK WC1E 6AU

Phone: +44 7414118527

Email: a.butcher@ucl.ac.uk 


\section{Abstract}

Preoperative anaemia and perioperative red blood cell transfusions carry significant consequence when it comes to surgical outcomes. Establishment of patient-centred clinical pathways have been designed to harness and endorse good transfusion practice termed the three pillars of patient blood management (PBM). These focus on the timely and appropriate management of anaemia, prevention of blood loss and restrictive transfusion where appropriate. This article reviews the current evidence and ongoing research in the field of PBM in surgery. Strategies to implement PBM have shown significant benefits in appropriate transfusion practice, reduced costs and improved patient length of hospital stay. Recently published national quality standards have recognised the importance of the PBM blueprint in surgery considering alternatives to red blood cell transfusion, active measures to reduce perioperative blood loss and the appropriate management of postoperative anaemia. Adopting PBM in surgical patients, should be paramount to reduce the risks posed by perioperative anaemia and blood transfusions. Principles of PBM help structure the interventions and decisions relating to anaemia and blood transfusion, but more importantly represent a paradigm shift towards a more considered approach to blood transfusion, acknowledging its risks, preventatives and alternatives.

\section{Why is Pre-Operative Anaemia a Problem?}

Pre-operative anaemia carries patient consequence when it comes to surgical outcomes. In the hospital setting, a third of elective surgical patients are admitted with coexisting anaemia, which alone is an established risk factor for a number of adverse outcomes. Whilst anaemia increases need for red blood cell (RBC) transfusion, anaemia is associated with increased patient morbidity and mortality correlating with the degree of anaemia.

In the last few years there has been a stepwise increment in the quantity of publications, revealing good quality evidence of the independent association with worse outcome in patients who have preoperative anaemia across most surgical specialties, including orthopaedics, upper/lower GI, hepatobiliary, and gynaecology (Carson et al, 1996; Mussallam et al, 2011; Jans et al, 2013; Baron et al, 2014; Fowler et $a l, 2015)$. Prevalence of preoperative anaemia in the surgical population, when both genders are incorporated, sits at approximately 30\% (Munoz et al, 2011). In a secondary analysis of 39309 patients undergoing non-cardiac surgery in the European Surgical Outcomes Study (EuSOS), multivariable analysis showed that patients with severe or moderate anaemia had a higher in-hospital mortality than 
those with normal preoperative haemoglobin concentration: OR 2.28 (95\% CI; 2.06 to 3.85) and 1.99 (95\% CI; 1.67 to 2.37), respectively (Ferraris et al, 2012).

Preoperative anaemia is the strongest indicator for perioperative blood transfusion. The emphasis placed on recognising at risk patients and managing accordingly is supported by the association of anaesthetists of Great Britain and Ireland (AAGBI, 2016), NHS Blood and Transplant (NHSBT, 2013), British Society of Haematology (BSH; Kotzé et al, 2015) and National Institute for Health and Care Excellence (NICE; NICE Guideline 24, 2015). However, the current standard of care for anaemic patients during surgical admission is management by a RBC transfusion.

Establishment of patient-centred clinical pathways have been designed to harness and endorse good transfusion practice; termed the three pillars of patient blood management (PBM). These focus on the timely and appropriate management of anaemia, prevention of blood loss and restrictive transfusion where appropriate. In the setting of surgery, these three pillars of PBM align with preoperative, operative and post-operative care. Many centres globally, including those in Australia, Europe and the US have championed the PBM initiative, albeit with expected apprehension amongst clinicians. This is due to the overriding issues of hospital culture challenging new strategies, and the reluctance to implement PBM bundles due to the limited amount of evidence on whether these interventions do have a positive impact in patient outcome. This review focuses on the current evidence for practical implementation and safety of the PBM pillars in surgery and ongoing research in the field. 


\section{Patient blood management in Surgery}

Table 1. Implementing PBM in elective surgery.

\begin{tabular}{|c|c|c|}
\hline \multicolumn{3}{|l|}{ Pillar 1. Anaemia Management } \\
\hline Pre-operative & Intra-operative & \begin{tabular}{|l} 
Post-operative \\
\end{tabular} \\
\hline $\begin{array}{l}\text { Diagnosis of anaemia } \\
\text { (Ideally two weeks prior to } \\
\text { planned surgery) } \\
\text { - Identification of underlying } \\
\text { cause of anaemia: Perform } \\
\text { Full Blood Count (FBC) } \\
\text { O Performed by GP as } \\
\text { apart of referral } \\
\text { process OR initial } \\
\text { surgical outpatients } \\
\text { Educate } \\
\text { surgical/perioperative } \\
\text { teams which } \\
\text { procedures are most } \\
\text { likely to require } \\
\text { anaemia screening } \\
\text { e.g. major open } \\
\text { abdominal surgery } \\
\text { Diagnosis of IDA, } \\
\text { B12/Folate deficiency } \\
\text { Extended diagnosis of } \\
\text { anaemia e.g. further referral } \\
\text { to gastroenterology, } \\
\text { endoscopy, haematology } \\
\text { EPO Iron, B12/Folate, } \\
\text { - }\end{array}$ & $\begin{array}{l}\text { Optimising } \\
\text { cardiovascular and } \\
\text { pulmonary tolerance } \\
\text { - Haemodynamic } \\
\text { monitoring in high-risk } \\
\text { procedures/patients }\end{array}$ & 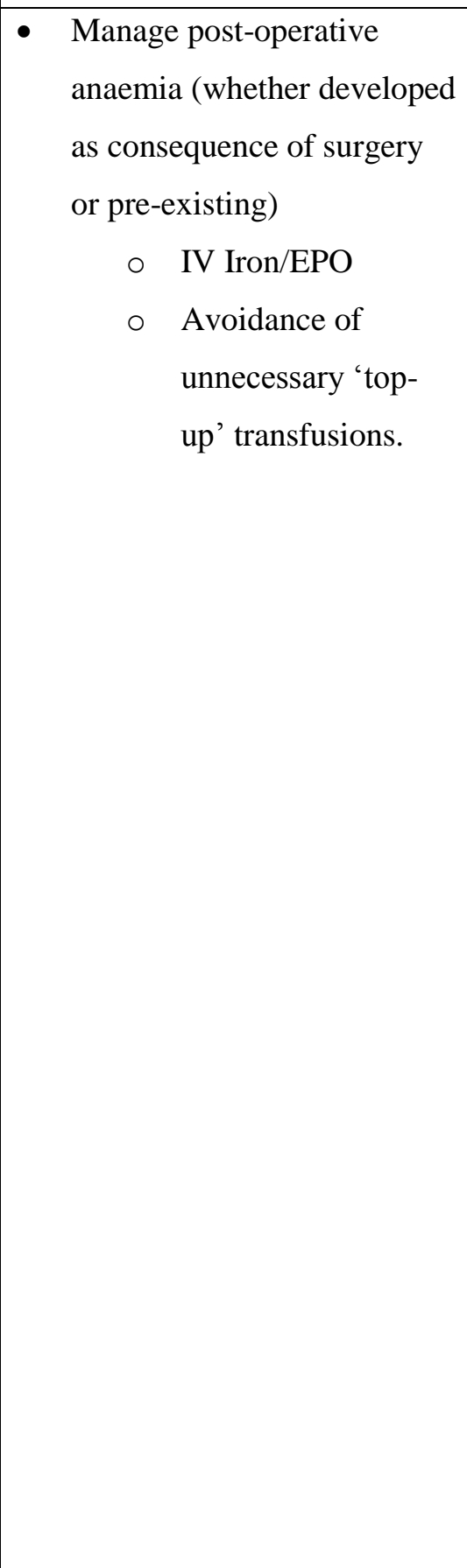 \\
\hline illar 2. Managing Perioperati & 18 & \\
\hline Pre-operative & Intra-operative & Post-operative \\
\hline
\end{tabular}




\begin{tabular}{|c|c|c|}
\hline $\begin{array}{l}\text { - Identifying at-risk patients } \\
\text { (surgical outpatients/pre- } \\
\text { operative assessment) } \\
\circ \text { Including full } \\
\text { medical and } \\
\text { pharmaceutical } \\
\text { review }\end{array}$ & 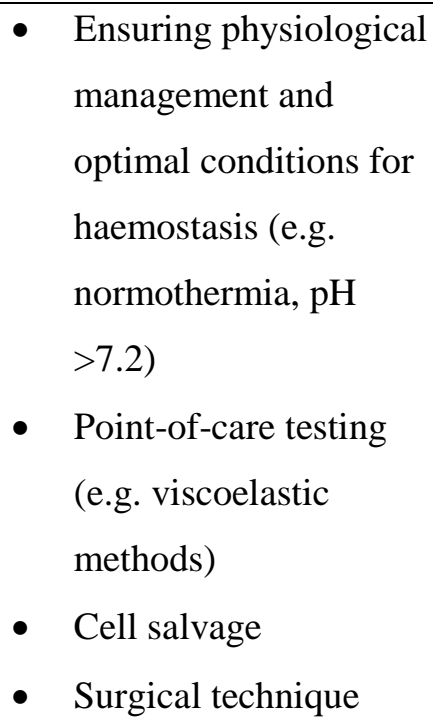 & $\begin{array}{ll}\text { - } & \text { Monitor and manage } \\
\text { ongoing bleeding e.g. cell } \\
\text { salvage } \\
\text { - } & \text { Maintain physiological } \\
\text { conditions } \\
\text { - } \\
\text { Minimise unnecessary } \\
\text { phlebotomy } \\
\text { Haemostasis/anticoagulation } \\
\text { management }\end{array}$ \\
\hline \multicolumn{3}{|c|}{ Pillar 3. Managing Post-Operative Anaemia } \\
\hline Pre-operative & Intra-operative & Post-operative \\
\hline $\begin{array}{l}\text { Patient-focused care - } \\
\text { identifying and optimising } \\
\text { patient's physiological } \\
\text { reserve }\end{array}$ & - Cell salvage & $\begin{array}{l}\text { Evidence-based transfusion } \\
\text { thresholds } \\
\text { - Manage IDA with IV Iron }\end{array}$ \\
\hline
\end{tabular}

Patient blood management is a globally recognised and WHO-endorsed concept (WHA63.12) that aims to manage the issues of pre-operative anaemia and blood transfusion by addressing quality and safety of transfusion practice. Strategies to implement PBM have shown significant benefits in appropriate transfusion practice, reduced costs and improved patient length of stay (Moskowitz et al, 2010; Theusinger et al, 2014; Goodnough, 2014; Gross et al, 2-15; Meybohm et al, 2016). This was best highlighted in the summary report from the Western Australian PBM initiative; a six-year educational jurisdiction wide program of PBM introduction was associated with a reduction in preoperative anaemia rates, reduced blood transfusion and overall blood product utilisation with associated reduction in length of hospital stay and improved patient outcomes (Leahy et al, 2017).

PBM guidelines and standards have developed from Australian lead professional associations. Providing detailed evidence-based information and recommendations on PBM in Australia, USA, and in several European nations (Kozek-Langenecker et al, 2013; Society for Advancement of Blood Management, 2013; Joint UK Blood Transfusion and Tissue Transplantation Services, 2014; American Society of Anesthesiologists, 2015; Hunt et al, 2015; Klein et al, 2016). A recent paper by Meybohm and colleagues, provided comprehensive bundles of PBM components encompassing more than 100 
different PBM measures to facilitate a stepwise implementation process of the most feasible measures (Meybohm et al, 2017). Practical recommendations targeting elective surgery have been summarised in Table 1 and will be expanded further in this review.

Recently published NICE quality standards for blood transfusion have also incorporated many features of the PBM blueprint including consideration of alternatives to blood transfusion, active measures to reduce perioperative blood loss and the appropriate management of postoperative anaemia (Table 2) (NICE, 2016).

Table 2. NICE Quality Standards (NICE, 2016).

\begin{tabular}{|l|l|}
\hline Standards & \\
\hline Statement 1 & $\begin{array}{l}\text { People with iron-deficiency anaemia who are having surgery are offered iron } \\
\text { supplementation before and after surgery. }\end{array}$ \\
\hline Statement 2 & $\begin{array}{l}\text { Adults who are having surgery and expected to have moderate blood loss are } \\
\text { offered tranexamic acid. }\end{array}$ \\
\hline Statement 3 & $\begin{array}{l}\text { People are clinically reassessed and have their haemoglobin levels checked } \\
\text { after each unit of red blood cells they receive, unless they are bleeding or are } \\
\text { on a chronic transfusion programme. }\end{array}$ \\
\hline Statement 4 & $\begin{array}{l}\text { People who may need or who have had a transfusion are given verbal and } \\
\text { written information about blood transfusion. }\end{array}$ \\
\hline
\end{tabular}

\section{Pillar 1 - Managing Pre-Operative Anaemia in the Surgical Patient}

Despite multiple guidelines and opinion documents on the management of pre-operative anaemia, or mandates such as those developed by NICE few provide pragmatic guidance or strong evidence-based platforms for the underlying determinant of anaemia in surgical patients.

The cause of anaemia in the pre-operative patient can often be complex and multifactorial. Nutritional deficiencies (e.g. Iron, B12, Folate) and chronic inflammatory states are the major contributors. The issue for diagnosis of iron deficiency anaemia (IDA) is inconsistency in the awareness and education surrounding the mechanisms of ID in surgical patients. Also, the absence of clear pathways and clinics in place to assist the diagnosis and treatment.

It is recommended that in elective surgical patients undergoing a major surgical procedure, with an expected blood loss $>500 \mathrm{mls}$ or a high probability of requiring a RBC transfusion, they have a full blood count (FBC), that is reviewed, at least two weeks prior to surgery (Muñoz et al, 2017). If a patient is found to have unexpected pre-operative anaemia or suboptimal haemoglobin $(\mathrm{Hb})$, surgery should be delayed in the setting of elective major procedures (characteristically for arthroplasty surgery) until 
satisfactory review and management is completed (Goodnough et al, 2011). Additionally, screening for common nutritional deficiencies; ferritin, B12 and folate should be standard practice, in order to direct care and achieve patient optimisation appropriately. Several diagnostic algorithms have been published with regards to this (Muñoz et al, 2017; Goodnough and Schrier, 2014). Unfortunately, these recommendations have been faced with many hurdles, often revealing the disengagement between primary and tertiary healthcare. In addition, many centres have emphasised the need to fast-track patients and provide same-day admission, contradicting the PBM principles of pre-operative patient optimisation. Surgical trials focusing on this aspect of PBM are ongoing with aim to provide more evidence surrounding the effectiveness of pre-operative anaemia management (Richards et al, 2015; Spahn et al, 2016; Bemelman et al, 2016).

\section{Treatment strategies for Iron Deficiency Anaemia}

The proposed treatment of pre-operative IDA in surgical patients with IV iron, has been of particular focus over the past few years as an approach to managing what we now recognise as an often complex, multifactorial condition.

The British Society of Gastroenterology and NICE guidance for the management of pre-operative IDA state that all patients should have iron supplementation to correct anaemia and replenish body stores, and the option of parenteral iron should be considered when oral preparations are not tolerated or ineffective (NICE, 2015; Ponikowski et al, 2015). Although, this may be effective to raise the [hb] in this setting there remains a significant paucity in the evidence as to whether using intravenous iron in the preoperative setting has any patient benefit and equipoise remains.

Oral iron remains the first-line, low-cost recommendation for IDA. Total body stores of iron are 3000$4000 \mathrm{mg}$ in healthy humans with a normal turnover / loss of $2 \mathrm{mg}$ per day. A systematic review has demonstrated that oral iron may reduce the proportion of patients requiring blood transfusion (Goddard et al, 2011). However, enteral iron is absorbed at a rate of $2-16 \mathrm{mg}$ per day, and 3-6 months of treatment can be required to provide $1000-2000 \mathrm{mg}$ to replenish the physiological reserve of iron as the bioavailability of ferrous iron is only $10-15 \%$. This is further reduced by poor absorption resulting from downregulation of duodenal absorption by inflammation, infection and chronic disease. Reduced uptake is one of the main reasons why oral iron may often fail to ameliorate anaemia in the surgical cohort. Further, compliance can also be poor owing to the common side-effects associated with oral iron salts, including abdominal pain, diarrhoea and constipation. Meta-analysis has shown oral iron salts have an OR of 2.32 (95\% CI; 1.74 to $3.08 ; P<0.001)$ compared with placebo for gastrointestinal side effects (Clevenger et al, 2016). 
Intravenous iron, has been demonstrated as an alternative treatment for correcting IDA in surgical patients. Several intravenous iron preparations are available, including iron polymaltose, ferumoxytol, ferric carboxymaltose, iron sucrose, and iron isomaltoside (Tolkien et al, 2015). Historically, parenteral iron preparations were associated with high rates of adverse effects including anaphylaxis, but these reactions were related to historical dextran-containing preparations. Modern carbohydrate preparations have a significantly improved safety profile with an overall anaphylaxis rate comparable to that for IV penicillin (Wang et al, 2015), about 3-10 per 100,000. Overall the sever adverse event rate for modern IV irons is about 3-4 times less than for a unit of blood. There is good evidence for their safety and efficacy in a range of conditions, including the perioperative setting (Auerbach et al, 2013).

A systematic review involving patients with anaemia undergoing surgery (including orthopaedics, colorectal, gynaecology, spinal, cardiac, upper GI and head and neck) demonstrated an increase in haemoglobin concentration and reduced risk of RBC transfusion (relative risk (RR) 0.74, 95\% CI; 0.62 to 0.88 ) with intravenous iron, especially when used with erythropoiesis stimulating agents (ESAs) or in patients with lower ferritin concentrations, without significant difference in mortality or serious adverse events (Lin et al, 2017).

Two recent surgical trials involving the use of IV iron to treat preoperative anaemia in patients undergoing colorectal and unspecified abdominal surgery, have shown conflicting responses in terms of transfusion outcomes (Froessler et al, 2016; Keeler et al, 2017). A trial by Froessler and colleagues show a significant reduction in RBC transfusion use by $60 \%$ in patients treated with IV iron preoperatively (Froessler et al, 2016). No difference was observed in secondary outcomes in terms of morbidity, mortality and quality of life, likely due to small recruitment size. The study by Keeler and authors, showed that IV iron while more effective in increasing $\mathrm{Hb}$ compared to oral iron, made no difference in terms of RBC transfusion use for colorectal surgery patients (Keeler et al, 2017). Both trials, small in population, have only identified primary outcomes in terms of RBC transfusion use, indicating that need for the continuation of larger ongoing trials and development of new studies investigating more insightful primary patient outcomes with focus on functional performance and quality of life (Richards et al, 2015; Spahn et al, 2016; Bemelman et al, 2016).

\section{Pillar 2 - Management of Intraoperative Bleeding}

Risk stratification of the surgical patient is important. Bleeding history must be included as part of the preoperative assessment, including a medication review, focusing on the use of anticoagulants. Intraoperative bleeding may be impacted by surgical techniques, anaesthetic blood loss reduction strategies e.g. point of care and cell salvage, and pharmacological management. 
The key factor in current practices is the increasing numbers of patients continued on anticoagulants and antiplatelets well into the perioperative period. Annually, approximately $10 \%$ of patients on any long-term oral anticoagulation will undergo surgery or other invasive procedure (Douketis et al, 2012). Anticoagulants are commonly prescribed agents for the prevention and treatment of a number of cardiovascular conditions. The BRIDGE study showed that patients on warfarin undergoing elective invasive procedure, foregoing bridging anticoagulation, faired no different in terms of reducing arterial thromboembolism and demonstrated reduced bleeding risk (Douketis et al, 2015).

\section{Point of care testing}

The guided management of coagulopathy through the use of point of care testing has shown to be a valuable tool. Unlike the conventional means of coagulation analysis, which is prolonged and often inaccurate, the development of viscoelastic testing (this allows changes of a blood clots tensile strength to be measured over time) now provides real time and rapid analysis of the dynamics of clot formation. In recent years, an increase in the worldwide use of viscoelastic testing such as thromboelastography $\left(\mathrm{TEG}^{\circledR}\right)$ and rotational thromboelastography $\left(\mathrm{ROTEM}^{\circledR}\right)$, which give a rapid description of the cellbased model of coagulation together with both cellular and humeral contributions to coagulation. Administration of fresh frozen plasma, platelets, cryopreciptate, factor concentrates and antifibrinolytic drugs can be guided by specific patterns of viscoelastic testing measurements. At present, NICE guidelines currently only recommend the use of viscoelastic testing in cardiac surgery (NICE, 2014). However, recent meta-analysis despite showing potential to reduce the requirement of blood products and mortality, demonstrate that the trials of evidence these guidelines are based on are low-quality, lowpower and carry high bias (Wikkelsø et al, 2017). Trial for guided therapy in specialty areas such as trauma and obstetrics are ongoing.

\section{Cell salvage}

If anticipated blood loss is great than $500 \mathrm{ml}$ or $>20 \%$ of the estimated blood volume, the use of intraoperative cell salvage is advocated (Klein et al,2016). It is a commonly used technique in cardiac surgery but less so in other areas, for no good reason. Cell salvage is performed with the use of a double lumen suction device to collect blood. Blood is stored within a reservoir with added anticoagulants. Once enough blood is collected, RBCs are washed, filtered, suspended in saline and reinfused back into the patient. The efficiency of cell salvage is improved with the use of antifibrinolytic drugs and the use of tranexamic acid (TXA) as recommended by NICE (NICE, 2015). A Cochrane review found that the 
use of cell salvage reduced the rate of allogenic RBC transfusion by $38 \%$ (RR $0.62,95 \% \mathrm{CI}$; 0.55 to 0.70), leading to an average saving of 0.68 units of RBCs per patients (Weighted mean difference -0.68; 95\% CI; -0.88 to -0.49 ) (Carless et al, 2010). In disciplines such as orthopaedic surgery, the risk reduction was $55 \%$.

Concerns have been raised surrounding the issues of re-transfused blood, and the potential harmful reintroduction of substances aspirated from the surgical field, including bacteria and malignant cells. Studies have shown that, despite the aspiration of microbiologically contaminated blood, there is no increase in positive cultures or postoperative infection, even though the washing phase is unable to eliminate all bacteria (Bowley et al, 2006; Feltracco et al, 2007). Furthermore, a recent systematic review emphasising the use of leucocyte depletion filters to eliminate tumour cells should be used, and demonstrated no association with increased risk of tumour dissemination or metastases (Kumar et al, 2014). European Society of Anaesthesiology guidelines suggest that the decision to use salvaged blood potentially contaminated with bacteria or malignant cells should be made on an individual basis (KozekLangenecker et al, 2013). Reviews focusing on outcomes relating to mortality, reoperation for bleeding, infection, would complication, non-fatal myocardial infarction, thrombosis, stroke and length of hospital stay were not increased by cell salvage (Carless et al, 2010; Meybohm et al, 2016). Up to date meta-analyses on randomised controlled trials focusing on washed cell salvage in all surgical groups demonstrated a reduced rate of infection (Meybohm et al, 2016).

\section{Antifibrinolytics}

Perioperative bleeding is a major indication for RBC transfusions (Levy, 2006). To reduce blood loss a number of pharmacological agents are in use, which include the antifibrinolytic agents, TXA and $\varepsilon$ aminocaproic acid (EACA). These are synthetic lysine analogues that act to inhibit fibrinolysis by their action at the active sites on plasminogen, inhibiting the activation of plasmin. Tranexamic acid should be used prophylactically in major surgery where perioperative blood loss is predicted to high and has been shown to significantly reduce perioperative blood loss.

A significant decline in risk of death from haemorrhage with the early use of TXA in the trauma setting has been demonstrated. The clinical randomisation of an antifibrinolytic in significant haemorrhage (CRASH-2 trial) highlighted the benefit of early therapy with TXA (1 $\mathrm{g}$ followed by a 1-g infusion over 8 hours), significantly reducing the risk of death from haemorrhage and all-cause mortality in traumatic bleeding (Collaborators CT, 2010). This evidence has been extrapolated into other major intraoperative scenarios with the possibility of blood loss. The recent ATACAS trial, demonstrated that in cardiac surgery patients receiving TXA there was a significantly lower risk of bleeding complications and transfusion requirements, also reduce reoperation compared to placebo (Myles et al, 2017). No 
difference was observed in composite primary outcomes of mortality and thrombotic event within 30days of index surgery between TXA and placebo (RR 0.92; 95\% CI, 0.81 to 1.05 ).

Aprotinin is a potent, non-specific serine protease inhibitor, derived from bovine lung, with antifibrinolytic properties to directly inhibit plasmin. It was used in cardiac procedures until it was withdrawn from clinic use after the blood conservation using antifibrinolytics (BART) randomised trial showed an increase risk of death with its use (Fergusson et al, 2008). The results of that trial have been disputed and subsequently aprotinin has been re-licenced for use in myocardial revascularisation surgery (McMullan et al, 2013). In terms of efficacy, the Cochrane systematic review by Henry and colleagues, concluded that the use of antifibrinolytics significantly reduced the requirement of perioperative RBC transfusion by $32 \%$, similar for both aprotinin and TXA (Henry et al, 2011).

\section{Pillar 3 - The Postoperative period}

Continued effort to reduce blood loss should be ongoing into the postoperative period. Simple interventions to decrease iatrogenic blood loss reduce the incidence of anaemia. Reducing the frequency and volume of phlebotomy, particularly in critical care, can have an impact. Additional strategies include a reduction in the sample volume with the use of paediatric blood tubes, using continuous sampling lines with small dead-space volumes (for arterial line samples) and evaluation of the requirement for each blood test according to clinical need (Raad et al, 2016). Blood loss into drains is another area of interest. In orthopaedic surgery, the use of drain has been shown to increase blood transfusion requirements (Parker et al, 2004). In keeping with many enhanced recovery programmes, postoperative surgical drain use is decreasing. Cell salvage can also be used after operation, with retransfusion of blood from drains particularly in major orthopaedic surgery (Ashworth et al, 2010).

The surgical stress response, inflammation and infection may precipitate functional iron deficiency, similar manner to that of chronic disease. This may contribute to the development of or further worsen a pre-existing IDA. This may impede recovery and rehabilitation, lead to further post-operative complications including readmission or re-operation. It is unclear whether the implementation of restrictive transfusion practices may impact on optimal patient outcomes. Limited research has focused on the area of post-operative care care, and the role of IV iron. Recent randomised controlled trials involving in general elective and orthopaedic surgery (Khalafallah et al, 2016) and post-gastrectomy (Kim et al, 2017) show that patients receiving IV iron post-operatively, had a significant increase in $\mathrm{Hb}$ values four and twelve weeks after index surgery, respectively. Khalafallah and colleagues also showed a significant reduction in the requirement of blood transfusion in patients given IV iron compared to standard care (incidence rate ratio $0.10 ; 95 \% \mathrm{CI} ; 0.01-0.85$ ). This is in contrast to an earlier smaller 
study comparing IV vs. oral iron in orthopaedic surgery patients, showing no difference in blood transfusion requirements (Bisbe et al, 2014). Both studies exhibit significant heterogeneity, warranting further larger studies in this area.

\section{Efficacy and Safety of Implementing PBM in Surgery}

Red blood cell transfusion is a reliable and life-saving intervention that is effective in replacing blood loss but in the non bleeding patient whilst it may 'top up' haemoglobin $(\mathrm{Hb})$ levels, it does not address the underlying cause of the anaemia. Increasing evidence accumulated over the past decade shows that transfusion is independently associated with increased morbidity, mortality, hospital and ICU length of stay across various surgical populations (Kotze et al, 2012; Hofmann et al, 2012; Keeler et al, 2016; Papageorge et al, 2017). In addition, there are concerns surrounding increasing the risk of Transfusion Associated Circulatory Overload (TACO) also sepsis, and cancer recurrence in oncology patients. The implementation of PBM has highlighted the best practice to restrict the use of red blood cell transfusions and ensure every blood transfusion is appropriate.

Timely identification and appropriate management of preoperative anaemia as indicated in PBM mandates, has been shown to reduce the need for peri-operative blood transfusions, even with modest rises in $\mathrm{Hb}$ (Papageorge et al, 2017). In a systematic review of over 20000 patients with colorectal cancer, Acheson and colleagues found that 58.8\% of patients received blood transfusions (Acheson et $a l, 2016)$. Blood transfusion was associated with an increased all-cause mortality (OR 1.72, 95\% CI; 1.55 to $1.91 ; P<0.001)$ and an increased OR of cancer-related mortality, combined recurrencemetastasis-death, postoperative infection and surgical re-intervention, with a mean duration of observation of 62.8 (standard deviation (SD) 28.8) months in the analysed studies (Acheson et al, 2016).

A recent Cochrane review on the impact of liberal transfusion strategies (typical transfusion trigger $\mathrm{Hb}$ 90-100g/L) with more restrictive strategies (typically transfusion trigger $70-80 \mathrm{~g} / \mathrm{L}$ ), demonstrated that of the 31 trials involving 12,587 participants, no evidence of difference in patient outcomes was observed (Carson et al, 2016). Many of the trials exploring the effectiveness and safety of restrictive transfusion practices often rely on the $\mathrm{Hb}$ value, regardless of whether there is active bleeding. The analysed trials involve broad clinical indications, not exclusive to elective surgery, such as, critical care, where the indications to transfuse and what the end-goal is to achieve varies between patients. Additionally, it must be made aware that $\mathrm{Hb}$ may be an unreliable biomarker, in terms of active bleeding where it can remain falsely elevated in due to inadequate fluid resuscitation, or fall due to haemodilution intraoperatively (Klein et al, 2016). 
Although blood transfusions can be a life-saving therapy for some, each transfusion brings a small risk of serious reactions. In particular, serious cardiopulmonary complications, including transfusionrelated acute lung injury (TRALI) and transfusion-associated circulatory overload (TACO), which have both been identified as the leading cause of transfusion-associated death (Bolton-Maggs et al, 2016). In a recent multi-centre, retrospective analysis of almost 5000 transfusion episodes, $1.1 \%$ were associated with TACO, and $\underline{0.08 \% \text { with TRALI (Hendrickson et al, 2016). Other transfusion risks }}$ include anaphylaxis and hypotensive episodes, and milder events including febrile non-haemolytic, minor allergic and delayed serologic reactions.

\section{Conclusion}

Adopting PBM in surgical patients, should be paramount to reduce the risks posed by perioperative anaemia in red blood cell transfusions. The programme of PBM recently addressed in national blood transfusion guidelines and its active implementation has demonstrated both patient and health economic benefits. The decision to transfuse red blood cells should not be reflex reaction to a defined laboratory values, as it was often done in past practice but a considered risk-benefit decision taken on individual patient basis. The principles of PBM help structure the interventions and decision relating to anaemia and blood transfusion, but more importantly represent a paradigm shift towards a more considered approach to blood transfusion, acknowledging its risks, preventatives and alternatives.

\section{Acknowledgements}

$\mathrm{AB}$ and TR have contributed equally to this manuscript. 


\section{References}

- Acheson AG, Brookes MJ, Spahn DR. (2012). Effects of allogeneic red blood cell transfusions on clinical outcomes in patients undergoing colorectal cancer surgery. Ann Surg, 256: 235-244.

- American Society of Anesthesiologists Task Force on Perioperative Blood Management. Practice guidelines for perioperative blood management: an updated report by the American Society of Anesthesiologists Task Force on Perioperative Blood Management. Anesthesiology. (2015); $122: 241-75$.

- Ashworth A, Klein AA. (2010). Cell salvage as part of a blood conservation strategy in anaesthesia. Br J Anaesth, 105: 401-416.

- Auerbach M, Goodnough LT, Shander A. (2013). Iron: the new advances in therapy. Best Pract Res Clin Anaesthesiol, 27: 131-140.

- Baron DM, Hochrieser H, Posch M Et al. (2014) Preoperative anaemia is associated with poor clinical outcome in non-cardiac surgery patients. BJA, 113 (3): 416-423.

- Beattie WS, Karkouti K, Wijeysundera DN, Tait G. (2009). Risk associated with preoperative anemia in noncardiac surgery: a single-center cohort study. Anesthesiology, 110:574-581.

- Bemelman WA. Trial Comparing Ferric(III)Carboxymaltose Infusion With Oral Iron Suppletion as Treatment of Anaemia (FIT). ClinicalTrials.gov Identifier: NCT02243735, https:/www.clinicaltrials.gov/ct2/show/NCT02243735?term=iron\&type=Intr\&cond=surgery\&int $\underline{\mathrm{r}=\mathrm{iron} \& \mathrm{age}=12 \& \mathrm{rank}=16}$ (Accessed 22 April 2017).

- Bisbe E, Moltó L, Arroyo R, Muniesa JM, Tejero M. (2014). Randomized trial comparing ferric carboxymaltose vs oral ferrous glycine sulphate for postoperative anaemia after total knee arthroplasty. Br J Anaesth, 113(3):402-9.

- Blanc B, Finch CA, Hallberg L, et al. (1968) Nutritional anaemias. Report of a WHO scientific group. WHO Technical Report Series, 405: 1-40.

- Bolton-Maggs (Ed) D Poles et al. on behalf of the Serious Hazards of Transfusion (SHOT) Steering Group. The 2016 Annual SHOT Report (2017).

- Bowley DM, Barker P, Boffard KD. (2006). Intraoperative blood salvage in penetrating abdominal trauma: a randomized, controlled trial. World J Surg, 30:1074-80. doi:10.1007/s00268-005-04662 .

- Camaschella C. (2015). Iron-deficiency anemia. New England Journal of Medicine, 372: 1832-43.

- Carless PA, Henry DA, Moxey AJ, O’Connell D, Brown T, Fergusson DA. (2010). Cell salvage for minimising perioperative allogeneic blood transfusion. Cochrane Database Syst Rev, (4)CD001888. 
- Carson J, Duff A, Poses RM, Berli JA, Spence RK, Trout R et al. (1996) Effect of anaemia and cardiovascular disease on surgical mortality and morbidity. Lancet, 348(9034): 1055-1060.

- Carson J, Stanworth S, Roubinian N et al. (2016). Transfusion thresholds and other strategies for guiding allogenic red blood cell transfusion. Cochrane Database of Systematic Reviews. Issue 10.

- Cleland JG, Zhang J, Pellicori P, et al. (2016). Prevalence and outcomes of anaemia and hematinic deficiencies in patients with chronic heart failure. JAMA Cardiology, 1: 539-47.

- Clevenger B, Gurusamy K, Klein AA, Murphy GJ, Anker SD and Richards T. (2016). Systematic review and meta-analysis of iron therapy in anemic adults without chronic kidney disease: updated and abridged Cochrane review. Eur J Heart Fail, 18 (7): 774-785.

- Collaborators CT. (2010). Effects of tranexamic acid on death, vascular occlusive events, and blood transfusion in trauma patients with significant haemorrhage (CRASH-2): a randomised, placebocontrolled trial. Lancet, 376: 23-32.

- Douketis JD, Berger PB, Dunn AS, Jaffer AK, Spyropoulous AC, Becker RC, Ansell J. (2012). The perioperative management of antithrombotic therapy: American College of Chest Physicians evidence-based clinical practice guidelines ( $8^{\text {th }}$ editions). Chest; 133: 299S-339S.

- Douketis JD, Spyropoulos AC, Kaatz S, Becker RC, Caprini JA, Dunn AS et al. (2015). Perioperative Bridging Anticoagulation in Patients with Atrial Fibrillation. NEJM, 373: 823-833.

- Feltracco P, Michieletto E, Barbieri S, et al. (2007). Microbiologic contamination of intraoperative blood salvaged during liver transplantation. Transplant Proc, 39:1889-91. doi:10.1016/j.transproceed.2007.05.005.

- Fergusson DA, Hébert PC, Mazer CD et al. (2008). For the BART Investigators. New England Journal of Medicine, 358: 2319-31.

- Ferraris VA, Davenport DL, Saha SP et al. (2012). Surgical outcomes and transfusion of minimal amounts of blood in the operating room. Arch Surg, 147: 49-55.

- Fowler AJ, Ahmad T, Phull MK et al. (2015). Systematic review and meta-analysis between preoperative anaemia and mortality after surgery. Br J Surg, 102(11):1314-24.

- Froessler B, Palm P, Weber I, et al. (2016). The Important Role for Intravenous Iron in Perioperative Patient Blood Management in Major Abdominal Surgery: A Randomised Controlled Trial. Annals of Surgery. 264: 41-46.

- Goddard AF, James MW, McIntyre AS, Scott BB; British Society of Gastroenterology. (2011). Guidelines for the management of iron deficiency anaemia. Gut, 60: 1309-1316.

- Goodnough LT, Maniatis A, Earnshaw P et al. Detection, evaluation, and management of preoperative anaemia in the elective orthopaedic surgical patient: NATA Guidelines. $\mathrm{Br} J$ Anaesth. 2011; 106: 13-22.

- Goodnough LT, Shieh L, Hadhazy E, et al. (2014). Improved blood utilization using real-time clinical decision support. Transfusion, 54(5): 1358-65. 
- Goodnough LT, Schrier SL. Evaluation and management of anemia in the elderly. Am J Hematol. 2014; 89: 88-96.

- Gross, Seifert B, Hoffmann A, Spahn DR. (2015). Patient blood management in cardiac surgery results in fewer transfusions and better outcome. Transfusion, 55(5): 1075-81.

- Hendrickson JE, Roubinian NH, Chowdhury D, Brambilla D et al. (2016) Indicence of transfusion reactions: a multicentre study utilizing systematic active surveillance and expert adjudication. Transfusion, 56(10): 2587-2596.

- Henry DA, Carless PA, Moxey AJ, O’Connell D, Stokes BJ, Fergusson DA et al. (2011). Antifibrinolytic use for minimising perioperative allogeneic blood transfusion. Cochrane Database Syst Rev, (3)CD001886.

- Hofmann A, Farmer S, Towler SC. (2012). Strategies to pre-empt and reduce the use of blood products: An Australian perspective. Curr Opin Anaesthesiol. 25: 66-73.

- Hunt BJ, Allard S, Keeling D, Norfolk D, Stanworth SJ, Pendry K, et al. (2015). A practical guideline for the haematological management of major haemorrhage. Br J Haematol, 70:788-803.

- Isbister JP. (2015). The three-pillar matrix of patient blood management. ISBT, 10(S1): 286-294.

- Jans Ø, Jørgensen C, Kehlet H and Johansson PI. (2013) Role of preoperative anemia for risk of transfusion and postoperative morbidity in fast-track hip and knee arthroplasty. Transfusion, 54 (3): 717-726.

- Joint United Kingdom (UK) Blood Transfusion and Tissue Transplantation Services Professional Advisory Committee. Patient blood management - an evidence-based approach to patient care. (2014). http://www.transfusionguidelines.org.uk/uk-transfusion-committees/national-bloodtransfusion-committee/patient-blood-management. (Accessed 22 March 2017).

- Karkouti K, Wijeysundera DN and Beattie WS. (2008) Risk associated with preoperative anemia in cardiac surgery. Circulation, 17 (4): 478-484.

- Kassebaum NJ, Jasasaria R, Najhavi M et al. (2014) A systematic analysis of global anemia burden from 1990 to 2010. Blood, 123: 615-624.

- Keeler BD, Mishra A, Starou CL, Beeby S, Simpson JA. (2016). A cohort investigation of anaemia, treatment and the use of allogenic blood transfusion in colorectal cancer surgery. Annals of Medicine and Surgery, 6: 6-11.

- Keeler BD, Simpson JA, Ng O, et al. (2017). Randomized clinical trial of preoperative oral versus intravenous iron in anaemic patients with colorectal cancer. British Journal of Surgery, 104: 214221.

- Khalafallah AA, Yan C, Al-Badri R, Robinson E, Kirkby BE, Ingram E, Gray Z et al. (2016). Intravenous ferric carboxymaltose versus standard care in the management of postoperative anaemia: a prospective, open-label, randomised controlled trial. Lancet haematology, 3(9) e415e425. 
- Kim YW, Bae JM, Park YK, Yang HK, Yu W, Yook JH, et al. (2017). Effect of Intravenous Ferric Carboxymaltose on Hemoglobin Response Among Patients with Acute Isovolemic Anemia Following Gastrectomy: The FAIRY Randomised Clinical Trial. JAMA, 317(20): 2097-2104.

- Klein AA, Arnold P, Bingham RM, Brohi K, Clark R, Collis R, et al. (2016). AAGBI guidelines: the use of blood components and their alternatives 2016. Anaesthesia, 71:829-42.

- Kotzé A, Carter LA, Scally AJ. (2012). Effect of a patient blood management programme on preoperative anaemia, transfusion rate, and outcome after primary hip or knee arthroscopy: a quality improvement cycle. Br J Anaesth. 108: 943-952.

- Kotzé A, Harris A, Baker C et al. (2015). British Committee for Standards in Haematology Guidelines on the Identification and Management of Pre-Operative Anaemia. Br J Haematol, 171(3): 322-331.

- Kozek-Langenecker S, Bettelheim P, Giurea A, Halbmayer W, Haushofer A, Holzer P, et al. Interdisciplinary recommendations for the management of anaemia (patient blood management). (2013). http://www.oegari.at/web files/dateiarchiv/editor/interdisciplinary recommendations for the management of anaemia 2013.pdf. (Accessed 22 March 2017).

- Kozek-Langenecker SA, Afshari A, Albaladejo P, Santullano CA, De Robertis E, Filipescu DC et al. (2013). Management of severe perioperative bleeding: guidelines from the European Society of Anaesthesiology. Eur J Anaesthesiol, 30: 270-382.

- Kumar N, Chen Y, Zaw AS et al. (2014). Use of intraoperative cell-salvage for autologous blood transfusions in metastatic spine tumour surgery: a systematic review. Lancet Oncol, 15: e33-e41.

- Leahy MF, Hofmann A, Towler S, Trentino KM, Burrows SA, Swain SG et al. (2017). Improved outcomes and reduced costs associated with a health-system-wide patient blood management program: a retrospective observational study in four major adult tertiary-care hospitals. Transfusion, Feb 2. doi: 10.1111/trf.14006. (ePublication).

- Levy JH, Ramsay JG, Guyton RA. (2006). Aprotinin in cardiac surgery. New England Journal of Medicine, 354(18): 1953-7.

- Lin DM, Lin ES, Tran MH. (2013). Efficacy and safety of erythropoietin and intravenous iron in perioperative blood management: a systematic review. Transfus Med Rev, 27: 221-234.

- McMullan V, Alston RP III. (2013). Aprotinin and cardiac surgery: a sorry tale of evidence misused. Br J Anaesth, 110: 675-678.

- Meybohm P, Choorapoikayil S, Wessels A, Herrmann E, Zacharowski K, Spahn DR. (2016). Washed cell salvage in surgical patients. A review and meta-analysis of prospective randomized trials under PRISMA. Medicine, 95:e4490.

- Meybohm P, Herrmann E, Steinbicker AU, et al. (2016). Patient Blood Management is Associated with a Substantial Reduction of Red Blood Cell Utilization and Safe for Patient's Outcome: A Prospective, Multicenter Cohort Study With a Noninferiority Design. Ann Surg, 264(2):203-11. 
- Meybohm P, Richards T, Isbister J, Hofmann A, Shander A, Goodnough LT, et al. (2017). Patient blood management bundles to facilitate implementation. Transfus Med Rev, 31:62-71.

- Moskowitz D, McCullough J, Shander A, et al. (2010). The impact of blood conservation on outcomes in cardiac surgery: is it safe and effective? Ann Thorac Surg, 90(2): 451-8.

- Muñoz M, Acheson AG, Auerback M, Besser M, Habler O, Kehlet H, Liumbruno GM, Lasocki S, Meybohm P, Rao Baikady R, Richards T, Shander A, So-Osman C, Spahn DR, Klein AA. International Consensus statement on the peri-operative management of anaemia and iron deficiency. Anaesthesia. 2017; 72(2): 233-247.

- Munoz M, Gómez-Ramirez S, Campos A, Ruiz J and Liumbruno GM. (2015). Pre-operative anaemia: prevalence, consequences and approaches to management. Blood Transfusion, 13(3): 370-379.

- Musallam KM, Tamim HM, Richards T et al. (2011) Preoperative anaemia and postoperative outcomes in non-cardiac surgery: a retrospective cohort study. Lancet, 378(9800): 1396-407.

- Myles P, Smith JA, Forbes A, et al. (2017). Tranexamic Acid in Patients Undergoing CoronaryArtery Surgery. New England Journal of Medicine, 376: 136-148.

- National Institute for Health and Care Excellence. Blood transfusion. (NICE Quality Standard QS138). (2016). www.nice.org.uk/guidance/qs138. (Accessed 22 March 2017).

- National Institute for Health and Care Excellence. (2015). Blood transfusion. (NICE guideline 24). www.nice.org.uk/guidance/NG24. (Accessed 7 Februrary 2017)

- NHS Blood and Transplant. National comparative audit of blood transfusion. (2013). http://hospital.blood.co.uk/audits/national-comparative-audit/. (Accessed 22 March 2017)

- NICE (2014). Detecting, Monitoring and Managing Haemostasis: Viscoelastic Point-of-Care Testing (ROTEM, TEG and Sonoclot Systems). NICE Diagnostics Guidance 13. National Institute for Health and Care Excellence, London.

- Papageorge CM, Kennedy GD and Carchman EH. (2017). Preoperative blood transfusion is a predictor of worse short-term postoperative outcomes after colectomy. Surgery, 161 (4): 10671075.

- Parker MJ, Roberts CP, Hay D. (2004). Closed suction drainage for hip and knee arthroplasty. A meta-analysis. J Bone Joint Surg Am, 86-A: 1146-1152.

- Peyrin-Biroulet L, Williet N, Cacoub P. (2015). Guidelines on the diagnosis and treatment of iron deficiency across indications: a systematic review. American journal of clinical nutrition, 102: 1585-94.

- Ponikowski P, van Veldhuisen DJ, Comin-Colet J, et al. (2015). CONFIRM-HF Invesitgators. Beneficial effectsof long-term intravenous iron therapy with ferric carboxymaltose in patients with symptomatic heart failure and iron deficiency. European Heart Journal, 36: 657-68. 
- Preoperative Assessment and Patient Preparation: The Role of the Anaesthetist. AAGBI Safety Guidelines. https://www.aagbi.org/sites/default/files/preop2010.pdf. (Accessed 22 March 2017)

- Raad S, Elliot R, Dickerson E, Khan B, Diab K. (2016). Reduction of Laboratory Utilization in the Intensive Care Unit. J Intensive Care Med [ePub ahead of print]

- Richards T., Clevenger B., Keidan J., Collier T., Klein AA., Anker SD and Kelly, JD. (2015). PREVENTT: perioperative intravenous iron to treat anaemia in major surgery: study protocol for randomised control trial. Trials. 16: 254.

- Society for the Advancement of Blood Management (SABM). SABM administrative and clinical standards for patient blood management programs. https://www.sabm.org/publications - admin standards 2014. (Accessed 22 March 2017).

- Spahn D. Impact of Preoperative Treatment of Anemia and Iron Deficiency in Cardiac Surgery on Outcome. ClinicalTrials.gov Identifier: NCT02031289; https://www.clinicaltrials.gov/ct2/show/record/NCT02031289?term=anaemia\&type=Intr\&cond=S $\underline{\text { urgery\&intr=iron\&age }=12 \& \text { rank }=2}$ (Accessed 22 April 2017).

- Theusinger O, Kind S, Seifert B, et al. (2014). Patient blood management in orthopaedic surgery: a four-year follow-up of transfusion requirements and blood loss from 2008 to 2011 at the Balgrist University Hospital in Zurich, Switzerland. Blood Transfusion, 12(2): 195-203.

- Tolkien Z, Stecher L, Mander AP, Pereira DIA, Powell JJ. (2015). Ferrous sulfate supplementation causes significant gastrointestinal side-effects in adults: a systematic review and meta-analysis. PLoS One, 10: e0117383.

- Wang C, Graham DJ, Kane RC et al. (2015). Comparative Risk of Anaphylactic Reactions Associated With Intravenous Iron Products. JAMA, 314(19): 2062-2068.

- Wikkelsø A, Wetterslev J, Møller AM, Afshari A. (2017). Thromboelastography (TEG) or rotational thromboelastometry (ROTEM) to monitor haemostatic treatment in bleeding patients: a systematic review with meta-analysis and trial sequential analysis. Anaesthesia, 72(4): 519-531. 